Received: May 15, 2017; Accepted: Jun 09, 2017; Published: Jun 30, 2017; Paper Id.: IJMPERDAUG20173

\title{
INTRODUCTION
}

The flow field of an impeller passage of a centrifugal compressor is highly complex, three-dimensional and unsteady. A designer for a centrifugal compressor should have complete understanding on the influencing parameters, thereby one can design for better performance and efficiency. Tip clearance in centrifugal compressor causes the leakage of high pressure fluid from the pressure surface to suction surface of the impeller blade, making the flow field highly complex and affecting the performance. The required tip clearance can be obtained by shifting the casing in radial or axial or combined radial and axial directions. The performance of a compressor is inherently deteriorated by different loses that occur in different sections of the compressor stage. They are as follows: shock loss at an inducer inlet, wall friction loss within impeller channels, tip leakage, loss, secondary flow losses, mixing loss at diffuser inlet, wall friction loss within a diffuser, sudden expansion loss at a scroll inlet, wall friction loss within a scroll. Pampering (1973) concluded that clearance effects have pronounced influence on the performance of centrifugal and axial compressors compared to Reynolds number effects. Ishida and Senoo (1981) used two entirely different types of centrifugal blowers one with a radial blade impeller and the other with a backward blade impeller, measured the pressure distribution along the shroud at five flow coefficient and seven tip clearances. Senoo and Ishida (1987) observed the deterioration of compressor performance due to tip clearance of centrifugal impeller. They modified their theory on the tip clearance loss of a centrifugal impeller to include the variation of slip co-efficient of the impeller due to the tip clearance, by deriving a rational relationship between two empirical 
parameters in the theory. They have compared experimental data in the literature with prediction, to select corresponding flow rates of a compressor with different values of tip clearance loss. Heyes et al. (1992) observed the effect of blade tip geometry on the tip leakage flow in axial turbine cascades.

\section{COMPUTATIONAL METHODOLOGY}

The design details of the impeller which is used in the present investigation are given below: Inducer hub diameter, $\mathrm{d} 1_{\mathrm{h}}=160 \mathrm{~mm}$ Inducer tip diameter, $\mathrm{d} 1_{\mathrm{t}}=300 \mathrm{~mm}$ Impeller tip diameter, $\mathrm{d} 2=500 \mathrm{~mm}$ Blade height at the exit, $\mathrm{b}_{2}=34.7 \mathrm{~mm}$ No. of blades of impeller, $\mathrm{N}_{\mathrm{b}}=16$, Blade angle at inducer hub, $\beta 1_{\mathrm{h}}=53^{0}$ Blade angle at inducer tip, $\beta 1_{\mathrm{t}}=35^{0}$ Blade angle at exit, $\beta 2=90^{\circ}$ Thickness of the blade, $\mathrm{t}=3 \mathrm{~mm}$, Rotor speed, $\mathrm{N}=2000 \mathrm{rpm}$ All angles are with respect to the tangential direction. Centrifugal impeller with the above specifications with $3 \mathrm{~mm}$ thickness throughout the blade is shown in Figure 1. A single passage of the impeller with inlet at $50 \mathrm{~mm}$ ahead of the impeller and outlet at a distance of $35 \mathrm{~mm}$ downstream of impeller is shown in Figure 2. Casing is designed with a clearance of $0.7 \mathrm{~mm}$ throughout the blade height. The geometry from either of the CAD Systems and Blade Gen Model can be connected to the simulation model before setup option is activated. The next step is to generate the meshing solid body in which several methods are provided in ANSYS Workbench 15.0 these tools have the benefit of being highly automated along with having a moderate to high degree of user control. In this case maximum skewness is 0.7977 which is acceptable this value should be less than 0.9. Number of elements are 2310116. This much of elements require testing mesh independence. Inlet and outlet boundaries are pressure inlet with $0 \mathrm{~Pa}$ gauge pressure and mass flow $0.087 \mathrm{Kg} / \mathrm{s}$ at outlet respectively. Rotating domain interface used as frozen rotor. Stage for interfaces used for steady state simulations, rotational interaction between reference frames is not accounted for - i.e. the stationary domain "sees" the rotating components at a fixed position. Physical Time scaling value was observed to be taken as $10^{-3} \mathrm{~s}$. Accuracy criteria of RMS solution were decreased to $10^{-5}$ for better accuracy.

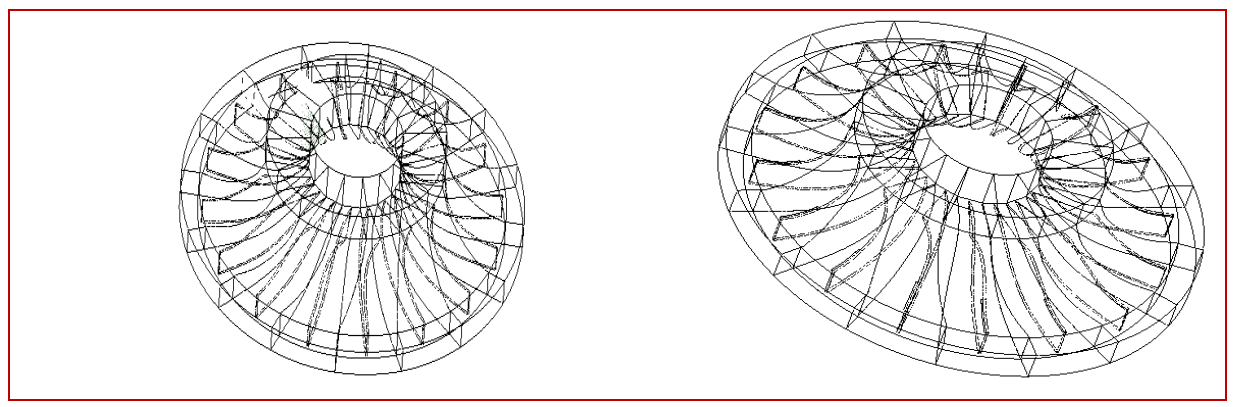

Figure 1: Centrifugal Compressor (without and with PS)

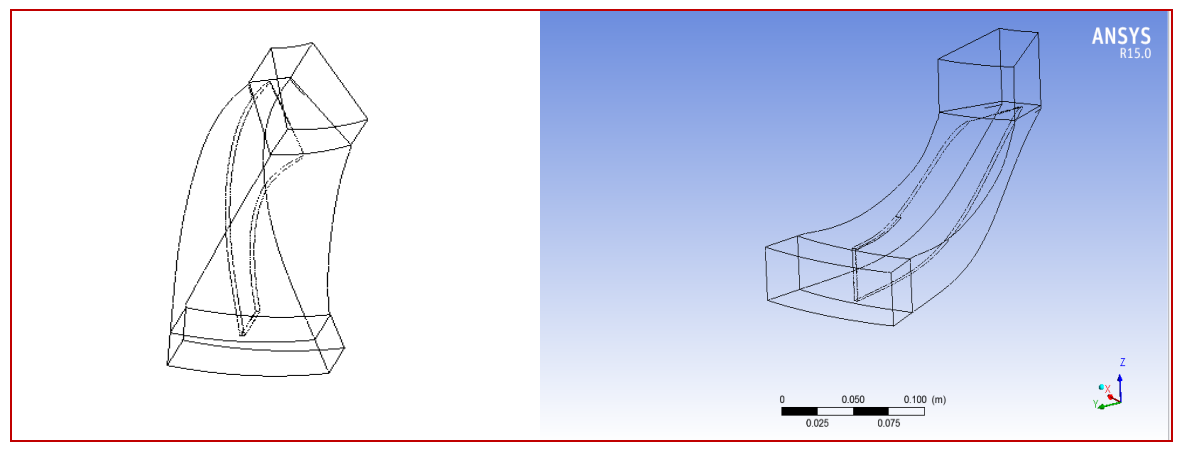

Figure 2: Computational Domain of Single Passage (without and with PS) 


\section{RESULTS AND DISCUSSIONS}

\section{Velocity Stream Lines}

Velocity streamlines inside the impeller with and without partial shroud for three tip clearances and flow coefficient of 0.34 is shown in figures 3 (a), (b) and (c). The streamlines show the movement of low energy fluid of the hub to shroud on both sides of the compressor blade. From the pressure surface side this low momentum fluid passes through the tip clearance region as a jet flow. The tip leakage flow interacts with the low momentum fluid on the suction surface side, causing the roll down and move towards the exit. At the rotor exit fluid flow pushes the low momentum fluid back into the impeller passage from the pressure surface side to suction surface side. This causes further deceleration of the flow from suction side. The strength and location of the wake region at the exit of impeller blade is heavily depended upon the tip leakage flow. When the vanes of diffuser are closer to the impeller the reverse flow enhances the tip leakage flow near the impeller exit. This is clearly observed from the streamlines pattern. The separated flow from the diffuser vane does not influence the impeller exit flow when there is a sufficient radial gap. At $\varphi=0.12,0.18$ and 0.28 velocity stream lines show the same trend as $\varphi=0.34$. But the velocity lines increases with increase in tip clearance is more as flow coefficient increases.

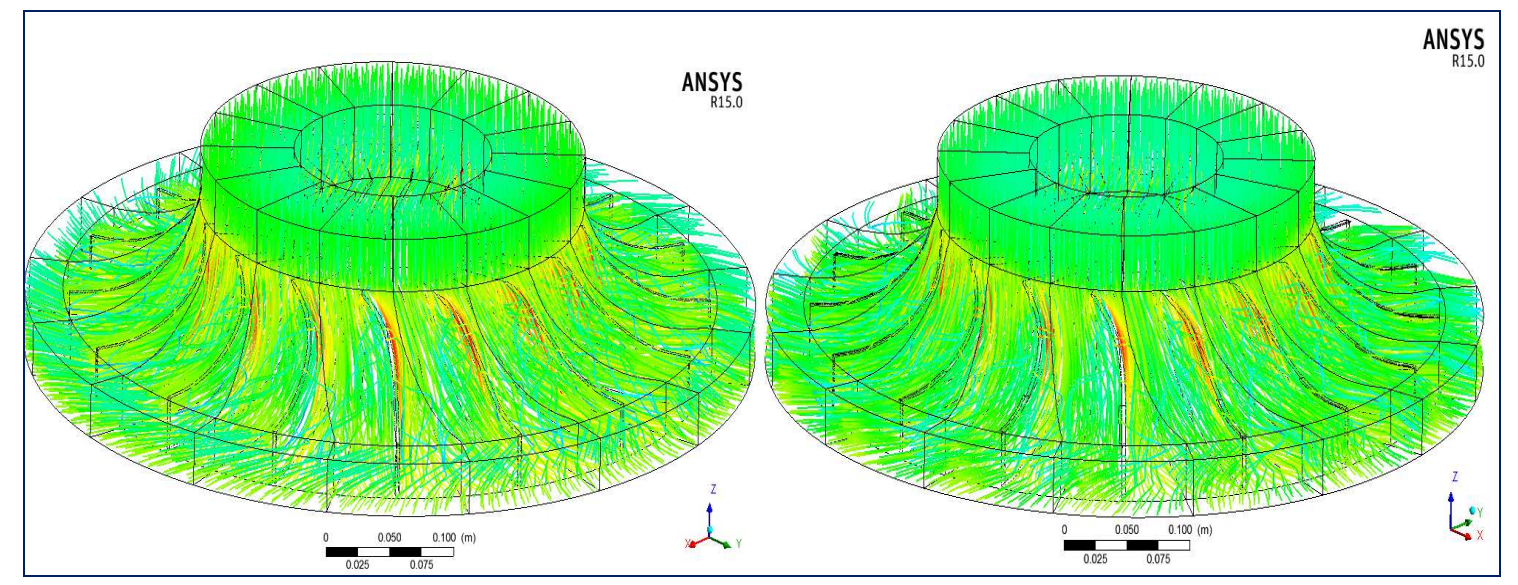

Figure 3(a): Velocity Streamlines Inside Impeller at $2.2 \%$ Tip Clearance for Without and with Partial Shroud at 0.34 Flow Coefficients

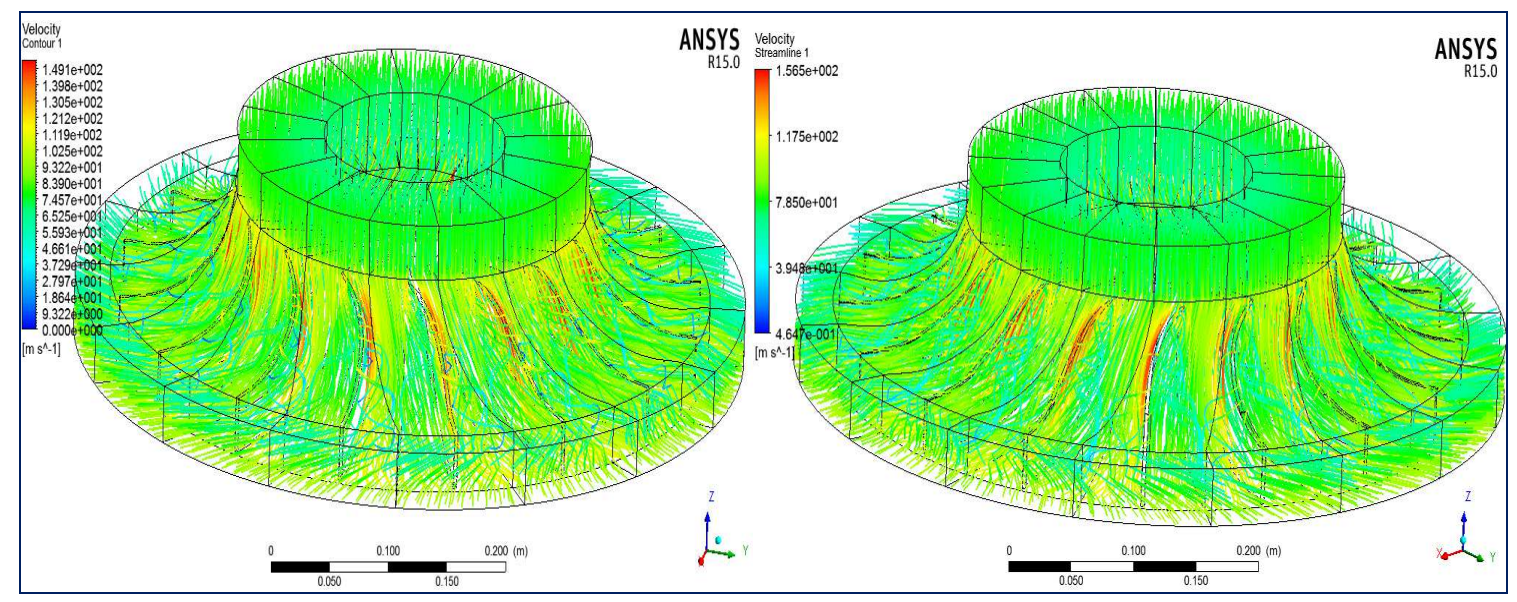

Figure 3 (b): Velocity Streamlines Inside Impeller at 5.1\% Tip Clearance for Without and with Partial Shroud at 0.34 Flow Coefficient 


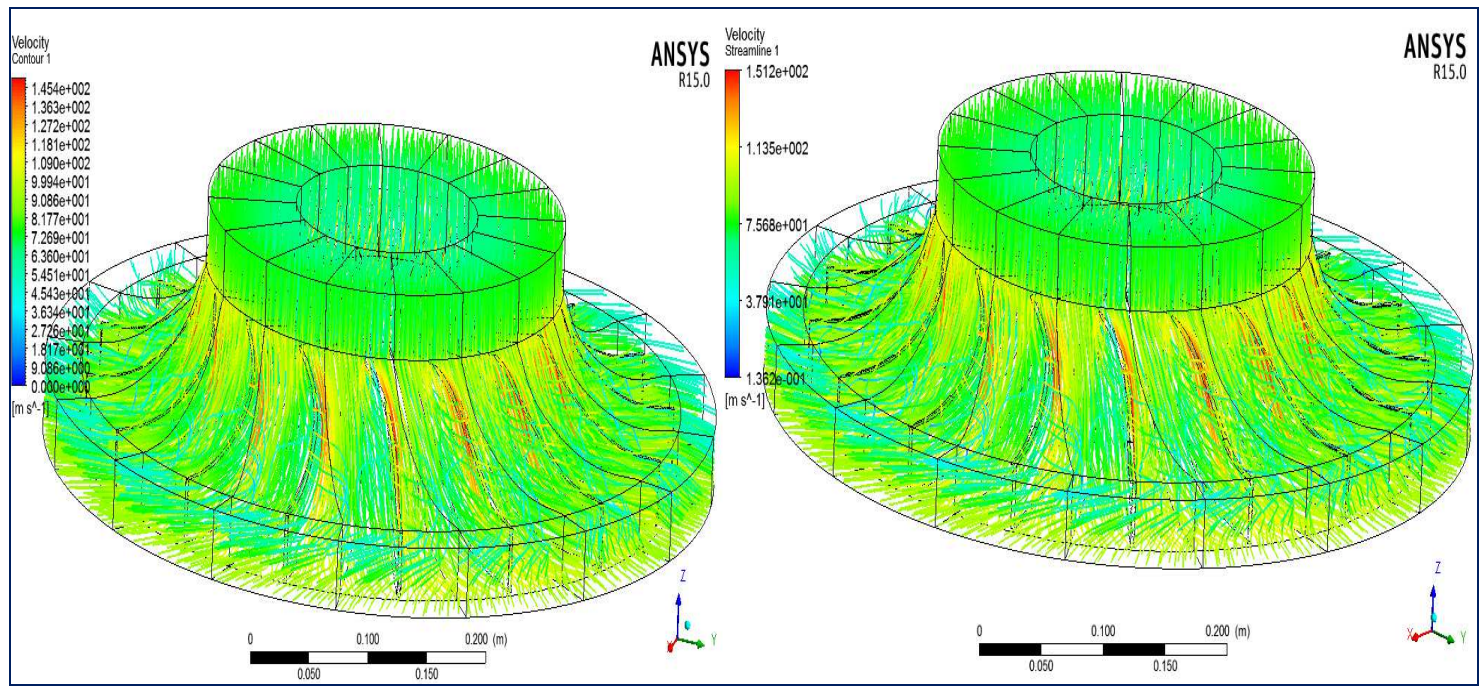

Figure 3 (c): Velocity Streamlines Inside Impeller at 7.9\% Tip Clearance for Without and with Partial Shroud at 0.34 Flow Coefficient

\section{Velocity Contours at Meridional Plane}

Velocity contours on a meridional plane for two configurations with and without partial shroud at $2.2 \%$ tip clearance is shown in figure 4. The contours show improved velocities on suction side with partial shroud. The low velocity passage wake area on suction side of the blade is reduced with without partial shroud on the tip of the blade. However, the velocity in the passage wake region is much lower with without partial shroud on the tip of the blade as more leakage flow is interacting with the main flow.

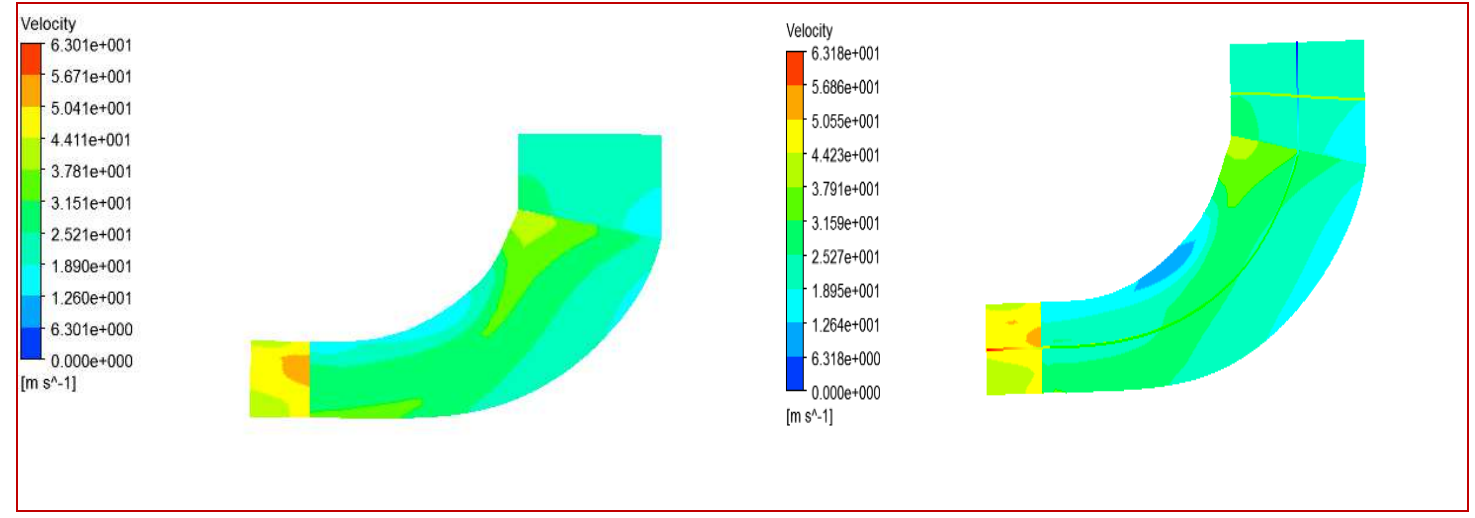

Figure 4: Velocity Contours at Meridional Plane of the Blade for $2.2 \%$ Tip Clearance for with and without Partial Shroud

\section{Velocity Vectors at Turbo Surface 1.8}

A velocity vector of turbo surface 1.8 at the exit of the impeller for four flow coefficients $\varphi=0.12,0.18,0.28$ and 0.34 and for the two tip clearances $\tau=2.2 \%$ and $7.9 \%$ for both configurations is shown in figures 5 (a), (b), (c), (d), (e), (f) and $(\mathrm{g})$. The fluid flows with a partial shroud on the tip of the blade velocities are higher on the suction surface than pressure surface because of centrifugal forces and blade curvature. For other tip clearances, leakage of flow from pressure side to suction side of the blade is higher through the tip gap of the blade is observed. For the tip clearance $7.9 \%$, near the suction side leakage flow is rolling up forming a wake. With the increase in the tip clearance $2.2 \%$ and $7.9 \%$, the wake 
region is increasing as leakage fluid mass flow rate increases. Circulating flow near the suction surface is observed, due to the strong centrifugal forces. At $7.9 \%$ clearance, the wake region is near the middle of the pitch and is significant. Downstream of the blade, absence of centrifugal force causes the flow nearly uniform. However, the passage wake is still observable at this meridional plane. At the trailing edge of the blade, velocity difference on the pressure and suction sides of the impeller is observed with jet and work flow. For $2.2 \%$ and $7.9 \%$ tip clearances, the high velocity of the fluid from pressure side to suction side through tip clearance is observed. But the velocity vectors increases with increase in tip clearance is more as flow coefficient increases. The velocity distribution is minimum near the hub and shroud is observed. Near the casing higher energy transfer is also observed. A similar trend is observed for all the flow coefficients.

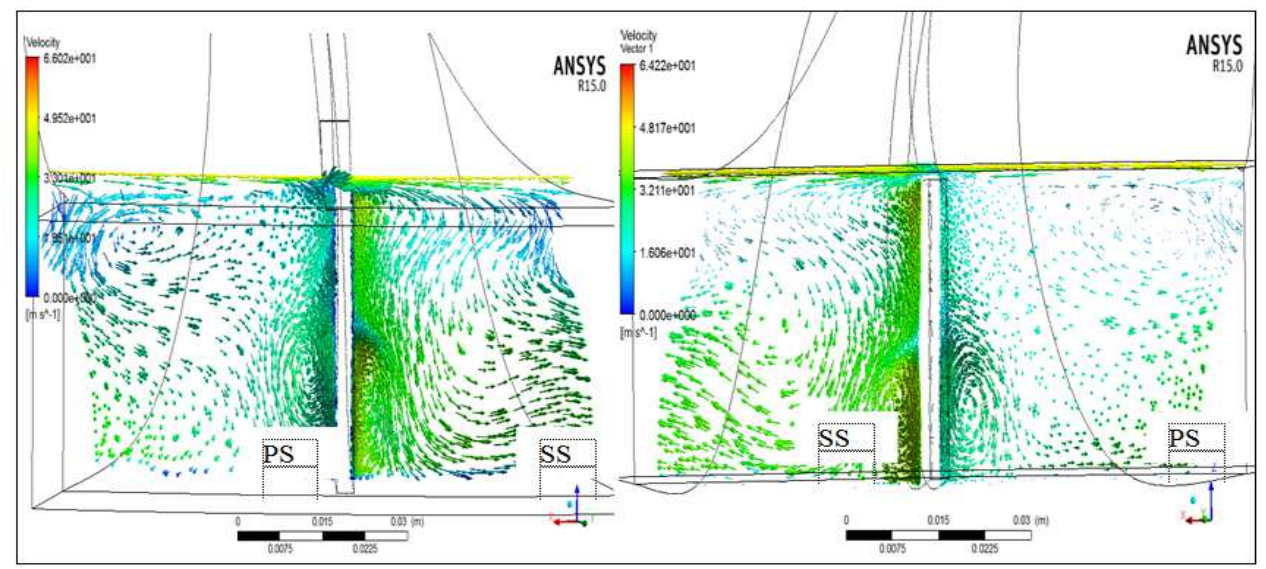

Figure 5(a): Velocity Vectors at Turbo Surface 1.8 of the Blade with and without Partial Shroud at 2.2\% Tip Clearance for Flow Coefficient 0.12

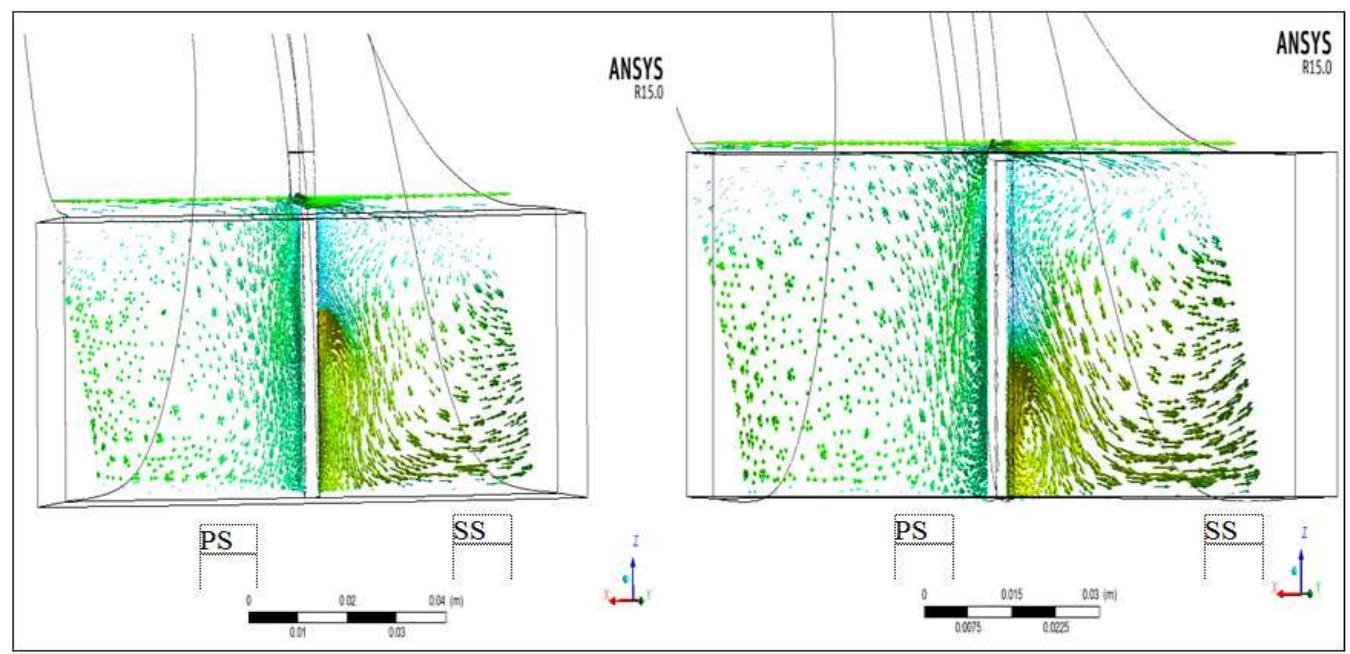

Figure 5(b): Velocity Vectors at Turbo Surface 1.8 of the Blade with and without Partial Shroud at 2.2\% Tip Clearance for Flow Coefficient 0.18 


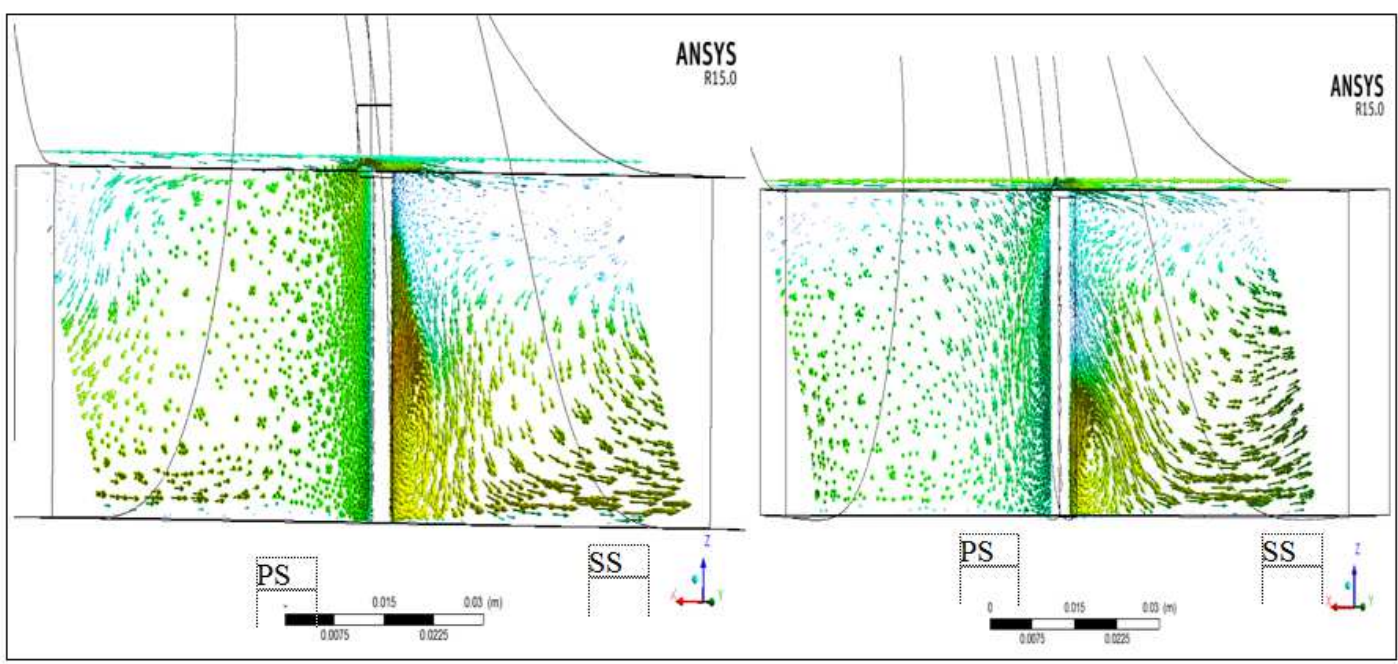

Figure 5(c): Velocity Vectors at Turbo Surface 1.8 of the Blade with and without Partial Shroud at 2.2\% Tip Clearance for Flow Coefficient 0.28

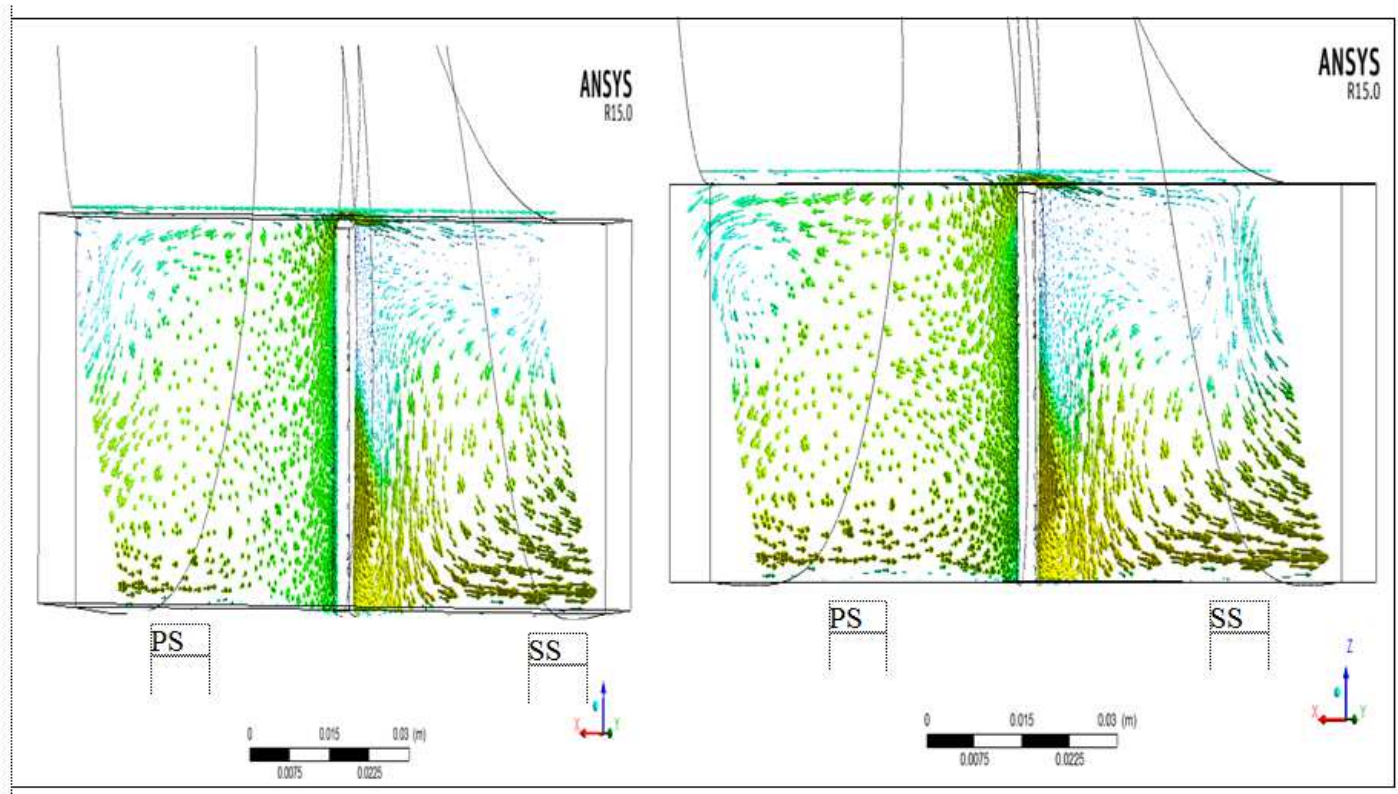

Figure 5(d): Velocity Vectors at Turbo Surface 1.8 of the Blade with and without Partial Shroud at 2.2\% Tip Clearance for Flow Coefficient 0.34 


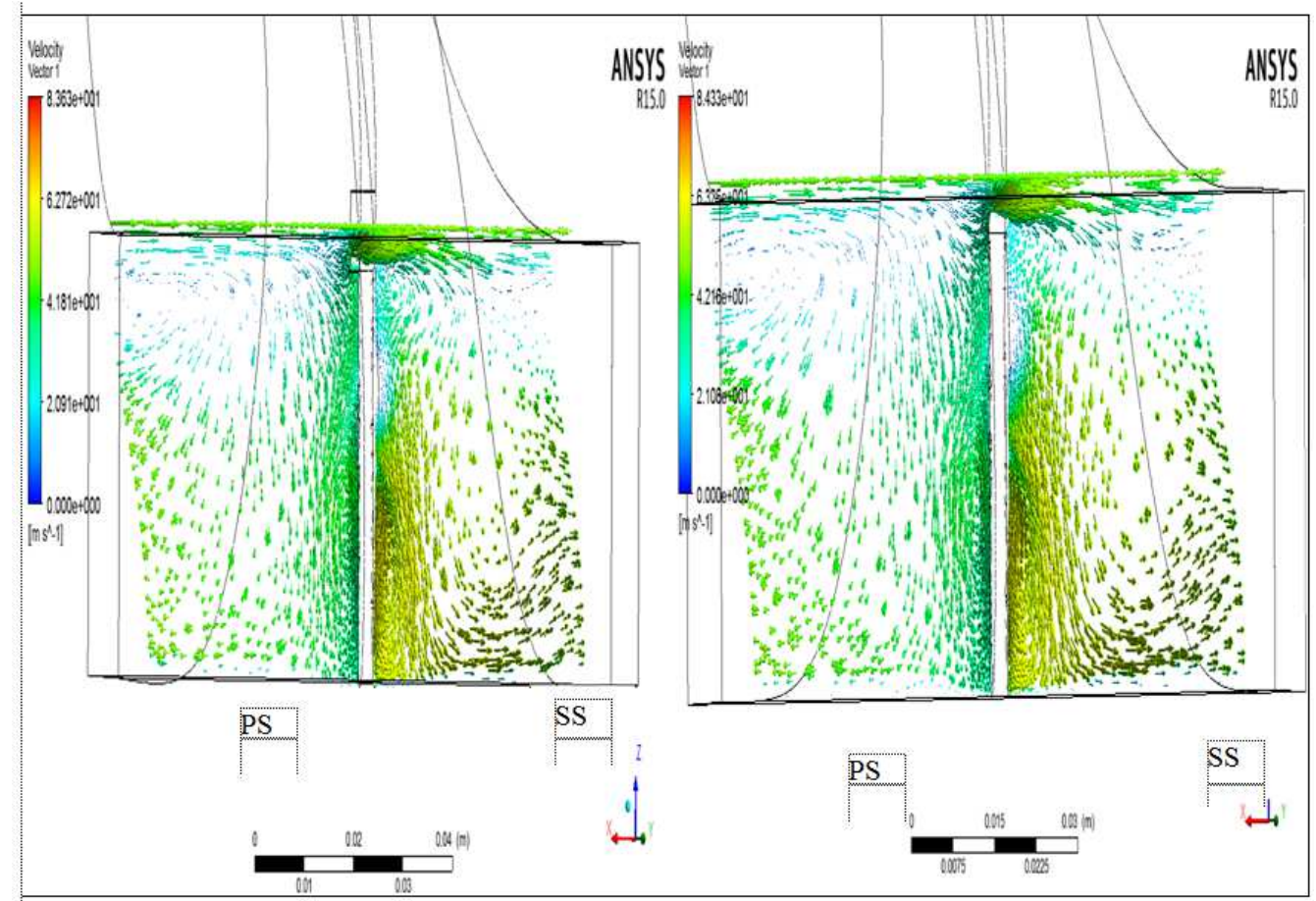

Figure 5(e): Velocity Vectors at Turbo Surface 1.8 of the Blade with and without Partial Shroud at 7.9\% Tip Clearance for Flow Coefficient 0.18

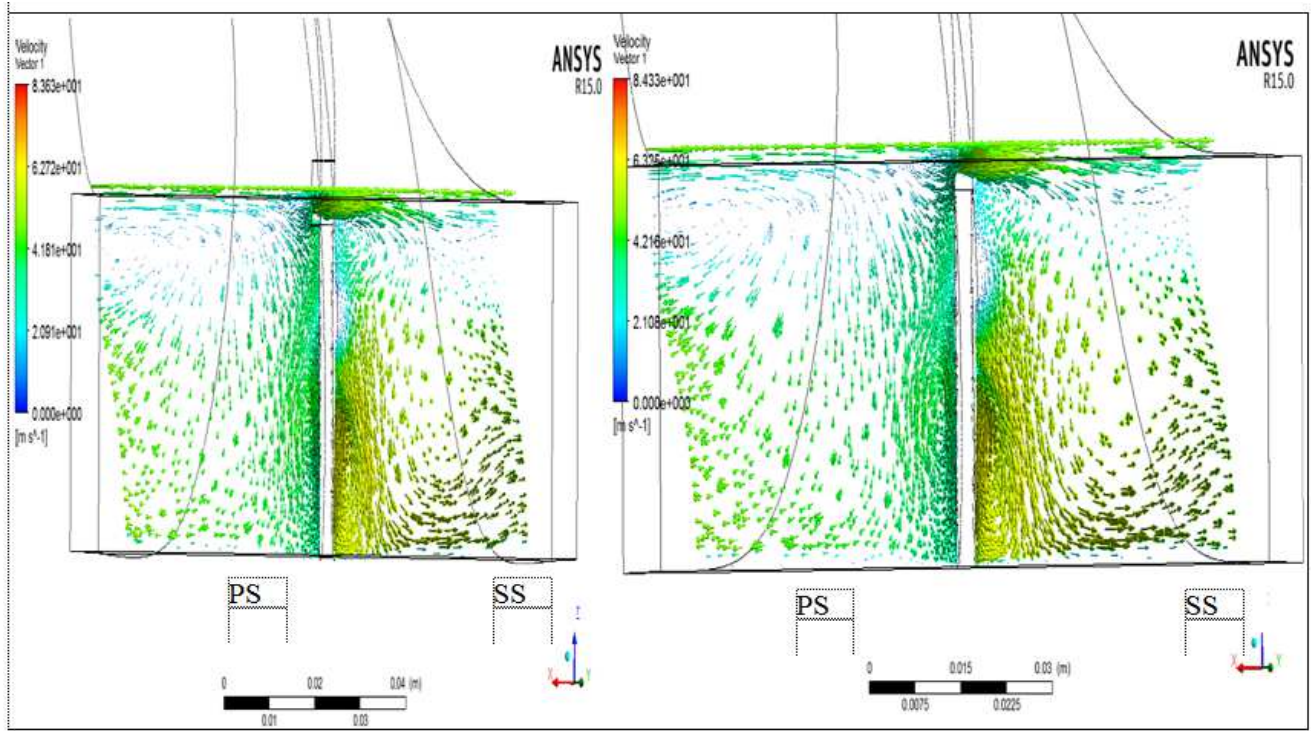

Figure 5(f): Velocity Vectors at Turbo Surface 1.8 of the Blade with and without Partial Shroud at 7.9\% Tip Clearance for Flow Coefficient 0.28 


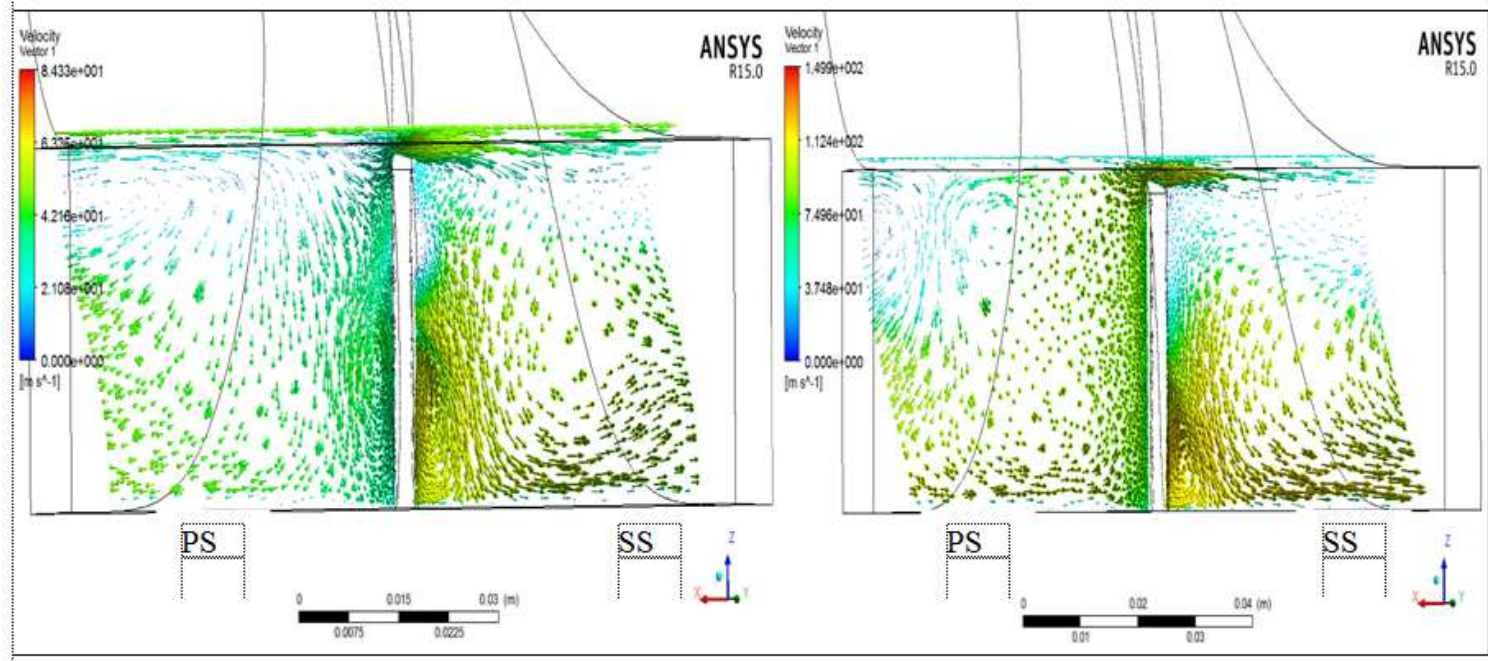

Figure 5(g): Velocity Vectors at Turbo Surface 1.8 of the Blade with and without Partial Shroud at $\mathbf{7 . 9 \%}$ Tip Clearance for Flow Coefficient 0.34

\section{Tangential Velocity Distribution}

A tangential velocity distribution from normalized hub to shroud without and with partial shroud for three tip clearances and for four flow coefficients is shown in figure 6 . The tangential velocity is a minimum near hub and shroud indicating the boundary layer. The maximum tangential velocity is observed near the shroud, indicating a higher energy transfer near shroud. However the tangential velocity moves away from the shroud as the tip clearance increases. Also the tangential velocity moves away from the casing as the flow coefficient decreases. From this figure, it is clearly shown that at a mass flow rate 0.018 and $0.14 \mathrm{~kg} / \mathrm{Sec}$, the tangential velocity is moving away from the shroud as tip clearance is increasing. The $2.2 \%$ clearance at a mass flow rate $0.285 \mathrm{~kg} / \mathrm{Suez}$ is showing a low tangential velocity as the mass flow rate falling beyond operating range. At flow coefficient $\phi=0.12$ the tangential velocity minimum is observed near the hub and shroud. The tangential velocity is increased with decreases tip clearance up to mid span and then it is decreasing with a decrease in tip clearance. The minimum tangential velocity at hub is increasing with the flow coefficient increase, whereas the tangential velocity at shroud is decreasing with flow coefficient increases. Also, the tangential velocity is decreasing with flow coefficient increase. 


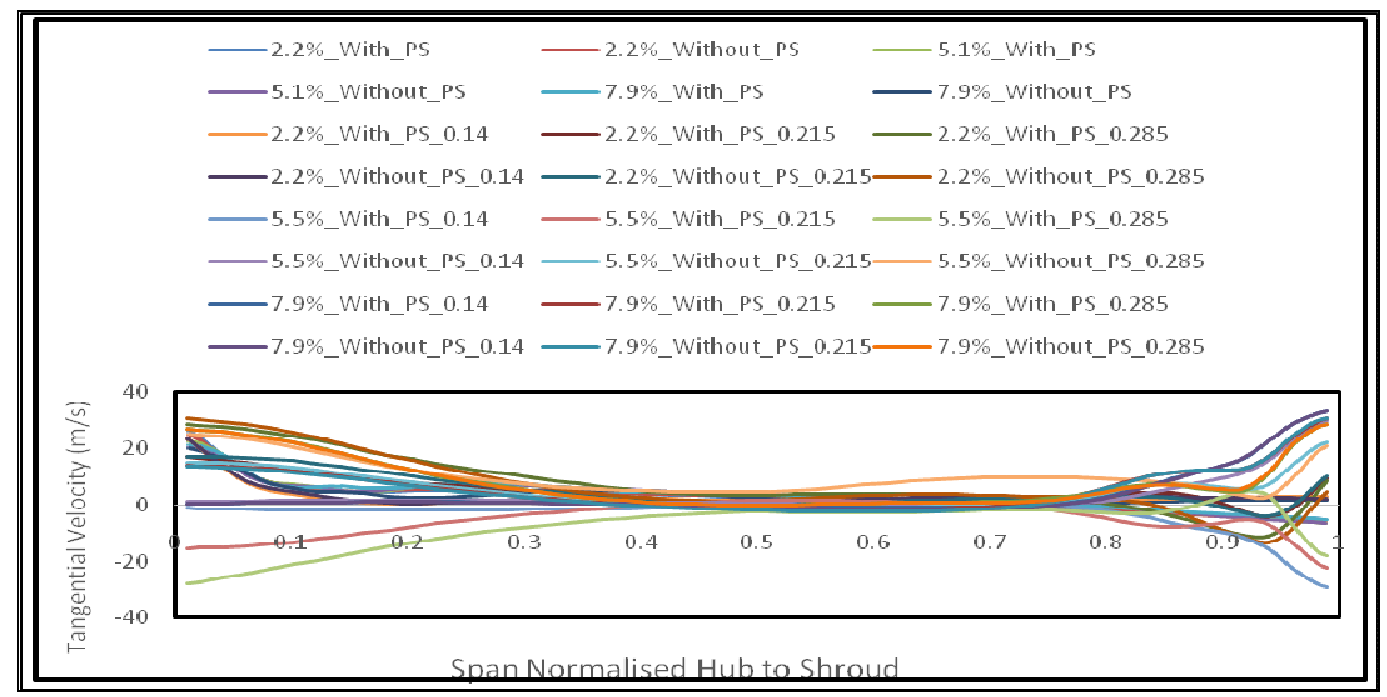

Figure 6: Tangential Velocity Distributions at Impeller Exit

\section{CONCLUSIONS}

The following major conclusions are drawn from this present experimental and computational investigation.

- Partial shrouds have more beneficial effects at $2.2 \%$ tip clearance for all the parameters studied by CFD are velocity contours on the shroud, velocity stream lines in the impeller, velocity vectors at turbo surface 1.8 , tangential velocity distribution and blade loading curves.

- Velocity streamlines inside the impeller with and without partial shroud from the pressure surface side this low momentum fluid pass through the tip clearance region as a jet flow. The tip leakage flow interacts with the low momentum fluid on the suction surface side, causing the roll down and move towards the exit.

- The velocity contours show improved velocities on suction side with partial shroud. The low velocity passage wake area on suction side of the blade is reduced with without partial shroud on the tip of the blade.

- The fluid flows with a partial shroud on the tip of the blade velocities are higher on the suction surface than pressure surface because of centrifugal forces and blade curvature. For other tip clearances, leakage of flow from pressure side to suction side of the blade is higher through the tip gap of the blade is observed.

- The minimum tangential velocity at hub is increasing with the flow coefficient increase, whereas the tangential velocity at shroud is decreasing with flow coefficient increases. Also, the tangential velocity is decreasing with flow coefficient increase.

\section{REFERENCES}

1. Eckardt, D., Detailed Flow Investigations within a High Speed Centrifugal Compressor Impeller, Trans. ASME, Jl. of Fluids Engg. 98, (1976) 390-402.

2. Adler, D., (1980) Status of Centrifugal Internal Aerodynamics, Part II: Experiments and Influence of Viscosity, Trans. ASME, Jl. of Engineering for Power, 102, 738-746

3. Shivaprasad, B. G. and B. R. Ramaprian, Turbulence Measurements in Boundary Layers along Mildly Curved Surfaces, ASME Paper 77-WA/FE-8. (1977). 
4. D. Eckardt, "Instantaneous measurements in the jet-wake discharge flow of a centrifugal compressor impeller," Journal of Engineering for Power, vol. 97, no. 3, (1975) pp. 337-345.

5. Johnson, M. W., and Moore, J., "The development of wake flow in a centrifugal compressor" ASME Journal of Engineering for Power, Vol. 102, (1980), pp. 383-390.

6. Johnson, M. W. and J. Moore, Secondary Flow Mixing Losses in a Centrifugal Impeller, Trans. ASME, Jl. of Engg. for Power, 105, (1983) 24-32.

7. Rene Hunziker, the operational stability of a centrifugal compressor and its dependence on the characteristics of the sub components, Trans. ASME, Jl. of Engg. for Power, 93-GT-284 (1993) 24-27.

8. Maksoud, T, M. A. and M. W. Johnson, Mean and Turbulent Flow Measurements within the Vaneless Diffuser of a Centrifugal Compressor, Proc. I. Mech. Engineers., Part C, (1987) 175-182.

9. Ishida, M. and Y. Senoo, On the Pressure Losses due to the Tip Clearance of Centrifugal Blowers, Trans. ASME, Jl. of Engg. for Power, 103, (1981) 271-278. 